\title{
World Medical Association's Concern Regarding Effects of Ultrafine Particles and Vehicular Emissions: Report from 65th General Assembly in Durban, South Africa
}

\author{
Heinz Fuchsig ${ }^{1} \cdot$ Manfred Neuberger $^{2}$
}

Published online: 16 August 2017

(C) World Medical Association 2014, All Rights Reserved

\begin{abstract}
Recent predictions from the World Health Organization indicate urban air pollution is the cause of nearly four million deaths annually. In particular, diesel soot, abundant in ultrafine (nanoscale) size, is shown to be carcinogenic and affects the cardiovascular and respiratory systems. Diesel soot contains mainly black carbon and adsorbed carcinogenetic substances as PAHs. Furthermore, soot and methane are both recognized as remarkable greenhouse-effect drivers. In its 65th General Assembly, the World Medical Association (WMA) recommended a series of measures to its member organizations to follow through via their respective governments. The recommended measures include utilizing the best available technology (BAT) for all new diesel vehicles and soot-filter retrofits for all in-use engines, curbing on nanosize soot emission, and further scrutiny of health impacts due to ultrafine particles, instilling further preventing measures and public awareness programs, protection against ultrafine particles in aircraft cabins, trains and alike, and to shift urban traffic to public transportation systems.
\end{abstract}

Keywords World Medical Association · Ultrafine particles · Vehicular emissions · South Africa

Heinz Fuchsig

Heinz.Fuchsig@auva.at

Austrian Workers' Compensation Board, Vienna, Austria

2 Medical University of Vienna, Vienna, Austria

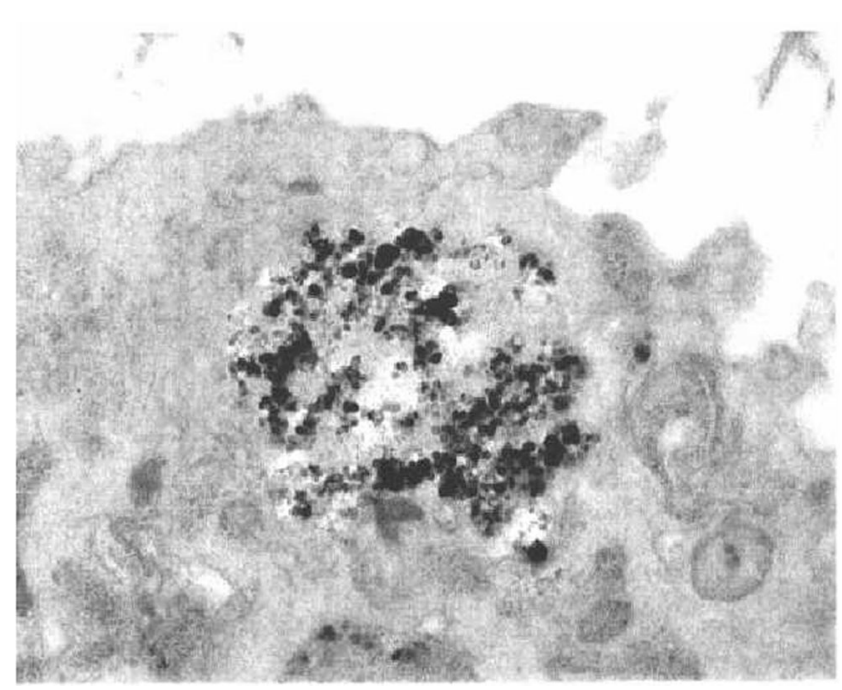

\section{Summary of General Assembly Report}

According to a recent estimate from the World Health Organization (WHO) [1], urban air pollution including pollution within vehicle cabins is responsible for 3.7 million deaths per year or $6.7 \%$ of the total worldwide mortality. In particular, diesel engine exhaust is carcinogenic to humans (group 1 carcinogen) [2] and exhibits a variety of toxic effects, predominantly in the cardiovascular system [3] and in the respiratory system [4]. Moreover, diesel soot and methane are acknowledged as particularly strong greenhouse-effect drivers, soot estimated to be 500,000 times more potent than $\mathrm{CO}_{2}$ (per unit 
mass) [5]. A group of notable scientists have urgently appealed [6] for a worldwide drive to reduce such pollutants.

Founded in 1947 and currently encompassing 111 National Medical Associations in their respective nations, the World Medical Association (WMA) (http://www.wma.net/en/ 60 about/) is an international organization representing physicians in their affiliated countries. With its secretariat located in Geneva-Ferney and in close proximity to WHO, WMA currently represents about 10 million physicians worldwide. As the legal representation of medical professionals in their respective countries, it is a WMA mission to serve the global population by pursuing improvements in public health worldwide. The annual WMA General Assembly is the highest ranking body of its decision-making.

At its 65th general assembly, the WMA in Durban, South Africa [7] unanimously adopted the following resolution, calling its member organizations to seek and demand from their respective governments the following specific actions:

\subsection{WMA Statement on the Prevention of Air Pollution Due to Vehicle Emissions}

1. Introduce best available technology (BAT) standards for all new diesel vehicles (both onroad and off-road) to reduce not only black carbon but also other toxic nanoparticles like metals.

2. Intensify retrofitting with BAT filters for all in-use engines.

3. Monitor and limit the concentration of nanosize soot particles in urban air.

4. Conduct epidemiological studies detecting and differentiating the health effects of ultrafine particles.

5. Build professional and public awareness of the importance of diesel soot and the existing methods of eliminating particles.

6. Contribute to developing strategies to protect people from soot particles in aircraft passenger cabins, trains, homes, and the general environment. These strategies should include plans to develop and increase use of public transportation.

7. In addition to acknowledging air pollution (only $12 \%$ of the people living in cities reporting on air quality reside in areas where exposure to ambient pollutants are below WHO air quality guideline levels [8]), WMA also emphasizes the tremendous economic loss of macroeconomic proportions due to reduced productivity and increased costs of health treatments. Despite new and strict regulations in a variety of countries to limit ultrafine particles by number count, a large fleet of in-use vehicles, onroad and off-road ones, construction equipment, and marine diesel engines are expected to continue polluting the public air. In many regions, concentrations of particulate matter have exceeded the WHO recommended daily limit 50-folds [9] and yearly limit 10-folds [10]. In cities like Peking, Teheran, Santiago, and Bogota, over 400,000 particles/ cc are regularly measured [11].

WMA believes a government-mandated retrofit program is the only effective solution to this pollution epidemic, necessary to improve air quality and health of the population at large and achievable within a reasonable time frame. For instance, about 85 million diesel engines are equipped with highly efficient diesel particle filters essentially eliminating soot nanoparticles, exemplified by a major retrofit program executed through the Swiss VERT certification.

Such programs have demonstrated that the benefits of retrofit regulations far exceed their costs, and by several folds. Ironically, the obstacles to retrofit programs in many cases have included the complexity of who reaps the benefits and who carries the burden of its costs.

WMA recommends governmental mandates to seek and execute appropriate ways and means in order to achieve the goals stated above.

Compliance with ethical standards The authors declare that they have no competing interests.

\section{References}

1. WHO 2015 Factsheet $\mathrm{N}^{\circ} 313$, update 03.2014, see also EFCAreport Nr. 24

2. IARC 2013 Nr. 105, http://monographs.iarc.fr/ENG/Monographs/ vol105/index.php

3. Brooks, et al.: AHA scientific statement. Circulation. 121, 23312378 (2010)

4. ERS 2010, http://www.erswhitebook.org/chapters/the-burden-oflung-disease/

5. Jacobson, M. (2005): J. Geophys. Res. 110, No. D14

6. Kerr, Science, 2012 and 5th assessment report IPCC: http://ar5-syr. ipcc.ch/

7. WMA 2014, Durban

8. World Health Organization 2014 report

9. Mike Walsh 2015, Car lines

10. WHO 2014 Factsheet $\mathrm{N}^{\circ} 313$, update http://www.who.int/ mediacentre/factsheets/fs313/en/, https://www.chinaabout.net/ pm2-5-level-pm2-5-china/

11. 19th ETH 2015 conference combustion generated nanoparticles, Zurich 